\title{
A A Rugged Oxygen Gas Sensor with Solid Reference for High Temperature Applications
}

\author{
A. K. M. S. Chowdhury, ${ }^{a}$ S. A. Akbar, ${ }^{\mathrm{a}, *, \mathrm{z}}$ S. Kapileshwar, ${ }^{\mathrm{a}}$ and J. R. Schorr ${ }^{\mathrm{b}}$ \\ ${ }^{a}$ Center for Industrial Sensors and Measurements, The Ohio State University, Columbus, Ohio 43210, USA \\ ${ }^{b}$ The Edward Orton Jr. Ceramic Foundation, Westerville, Ohio 43082, USA
}

\begin{abstract}
An oxygen sensor based on yttria-stabilized zirconia with $\mathrm{Ni}-\mathrm{NiO}$ mixture as a solid reference electrode for high temperature applications has been fabricated and tested. During high temperature use Ni reacts with inner Pt electrode and Pt lead wire, and affects the output signal of the sensor leading to a limited lifetime. This is the first time an $\mathrm{Al}_{2} \mathrm{O}_{3}$ isolation layer has been introduced in the design of an oxygen sensor. Use of this isolation layer prevents high temperature alloy formation between $\mathrm{Ni}$ and $\mathrm{Pt}$, leading to a significant enhancement in the performance and the stability of the sensor. The sensor shows fast response with good recovery characteristics in the temperature range of $600-1400^{\circ} \mathrm{C}$. However, after repeated tests over a longer period, the sensor performance degrades possibly due to grain growth and sintering of the inner electrode at high temperature.

(c) 2001 The Electrochemical Society. [DOI: 10.1149/1.1343105] All rights reserved.
\end{abstract}

Manuscript received August 9, 2000

The measurement and control of oxygen atmosphere inside a ceramic kiln are critical for the manufacture of useful ceramic products. ${ }^{1}$ Yttria-stabilized zirconia (YSZ)-based oxygen sensors are being used for this purpose. Such sensors can only measure oxygen concentrations in an area very near the wall of the kiln, as the sensor uses an air reference electrode and the length of the zirconia tube limits the location of measurement. Also, in the application environment, the sensor encounters severe operating conditions, such as high temperature, large temperature fluctuations, mixtures of gases, heavy dusts and vapors, and thermal shock. Recognizing the influence of these factors, the sensor probes must be specially designed, particularly those using a solid reference electrode.

The use of a galvanic cell for the determination of oxygen concentration in liquid steel was developed in many countries during the decade $1960-1970 .^{2}$ At that time a number of metal-metal oxide mixtures (e.g., $\mathrm{Mo}-\mathrm{MoO}_{2}, \mathrm{Cr}-\mathrm{Cr}_{2} \mathrm{O}_{3}$, etc.) were employed to fix the reference oxygen in a YSZ cell. These cells were exclusively designed for one-time use and oxygen was measured by dipping them in the molten steel. As they were used for one time only, their long-term stability was not an issue. Note here that $\mathrm{Cr}^{3}$ and $\mathrm{Mo}^{4}$ react with $\mathrm{Pt}$ electrodes and form compounds at relatively lower temperatures. Compound formation eventually leads to an unstable sensor.

Solid reference gives an equilibrium oxygen partial pressure at the operating temperature. The main advantage of solid reference over the air is that the metal-metal oxide mixture inherently produces extremely low $\mathrm{O}_{2}$ concentrations (trace) with respect to the test environment, thus producing a large pressure difference, leading to enhanced emf signals. If the partial pressure is too low, it is difficult to establish the equilibrium. If too high, the decomposition of metal oxide becomes significant. Thus, choosing a proper metal oxide reference electrode is very critical. Virtually this metal oxide acts as an oxygen pump, which provides a source of steady flow of oxygen. The partial pressure $\left(p_{\mathrm{O}_{2}}\right)$ generated by a given metal oxide can be determined by calculating the equilibrium constant for a given metal-metal oxide system. ${ }^{5}$ For example, the partial pressure of oxygen generated by a $\mathrm{Ni}-\mathrm{NiO}$ system is calculated to be of the order of $10^{-16} \mathrm{~atm}$. at $250^{\circ} \mathrm{C}{ }^{6}$ The sensor using a solid reference electrode can be represented by the following electrochemical cell

$$
\mathrm{O}_{2}, \mathrm{Pt} / \mathrm{YSZ} / \mathrm{Pt}, \mathrm{M}, \mathrm{M}_{x} \mathrm{O}_{y}
$$

Here $\mathrm{M}$ is a transition metal, such as $\mathrm{Ni}, \mathrm{Bi}, \mathrm{Mo}$, etc., and can be univalent or multivalent. In case of multivalent metal, $\mathrm{M}$ represents $\mathrm{W}, \mathrm{Fe}, \mathrm{Cr}, \mathrm{Mn}, \mathrm{Ba}$, etc. In this study, $\mathrm{Ni}-\mathrm{NiO}$ was used as the solid

\footnotetext{
* Electrochemical Society Active Member.

z E-mail: akbar.1@osu.edu
}

reference electrode. Other metal-metal oxide systems, such as Co$\mathrm{CoO}$ were studied and found unstable at the operating temperature. Thermodynamic data for $\mathrm{Ni}-\mathrm{NiO} / \mathrm{O}_{2}$ system is well established and is not presented here.

Based on the principle discussed above, preliminary work using $\mathrm{Ni}-\mathrm{NiO}$ was carried out in the authors' laboratory that shows promise. ${ }^{7}$ In that work the possibility of alloy formation between $\mathrm{Ni}$ and inner Pt electrode at relatively lower temperatures (around $700^{\circ} \mathrm{C}$ ) was disregarded. At high temperatures, the $\mathrm{Ni}-\mathrm{Pt}$ alloy formation ${ }^{8}$ is highly likely that would result in the degradation of the inner electrode in the long-term. This article addresses this problem specifically and presents a design for measuring oxygen concentrations in the temperature range of $600-1400^{\circ} \mathrm{C}$.

\section{Experimental}

Probe fabrication.-A typical oxygen sensor that was fabricated and tested can be represented as

(Sensing side) Pt electrode $\mid$ YSZ tube (one end closed), $\mathrm{Al}_{2} \mathrm{O}_{3}$ isolation $\mid \mathrm{Ni}-\mathrm{NiO}$ reference electrode $\mid \mathrm{Pt}$ electrode

Figure 1 shows the schematic of an oxygen sensor probe. A one-end closed YSZ tube (from Vesuvius McDanel; $12 \mathrm{~mm}$ o.d., 10 $\mathrm{mm}$ i.d., and $40 \mathrm{~mm}$ long) was used as the body of the sensor. $\mathrm{Ni}-\mathrm{NiO}$ was used as the solid reference electrode due to its high exchange current of oxygen ion. Fine Ni metal powder $(<100$ mesh, Johnson Mathey Company) was treated by $5 \% \mathrm{H}_{2}$ in $\mathrm{N}_{2}$ at $900^{\circ} \mathrm{C}$ to remove any surface oxide. Fine $\mathrm{NiO}$ powders $(<100$ mesh, Johnson Mathey Company) were treated at $1400^{\circ} \mathrm{C}$ for $1.5 \mathrm{~h}$ in air. For filling and isolation materials, $\mathrm{Al}_{2} \mathrm{O}_{3}$ fine powder $(<325$ mesh, Johnson Mathey Company) was used. $\mathrm{Al}_{2} \mathrm{O}_{3}$ powder was treated at $1500^{\circ} \mathrm{C}$ for $2 \mathrm{~h}$ in air.

Approximately two-thirds of the tube was filled with $\mathrm{Ni}-\mathrm{NiO}$ mixture $(9: 1)$. Pt-Ni binary phase diagram ${ }^{8}$ indicates formation of binary solid solution between $\mathrm{Ni}$ and $\mathrm{Pt}$ throughout the temperature range of $700-1400^{\circ} \mathrm{C}$. This solid solution formation was verified experimentally by heat treating $\mathrm{Ni}$ and $\mathrm{Pt}$ powders (50-50 wt \%), inside an evacuated glass tube at $1200^{\circ} \mathrm{C}$. The treatment was carried out at $1200^{\circ} \mathrm{C}$ because of the glass tube used. The results can be extrapolated to $1400^{\circ} \mathrm{C}$, as the phase diagram indicates that the same phase is formed at both temperatures (Ni-Pt solid solution). Using $\mathrm{X}$-ray diffraction (XRD) as a diagnostic tool, alloy formation was confirmed. To avoid this alloy formation, $\mathrm{Pt}$ wire was isolated from the Ni-NiO mixture using an $\mathrm{Al}_{2} \mathrm{O}_{3}$ tube (Fig. 1). A portion of the YSZ tube was filled first with $\mathrm{Al}_{2} \mathrm{O}_{3}$ powder covering the Pt contact inside the YSZ tube giving virtual isolation of Ni-Pt contacts. The 


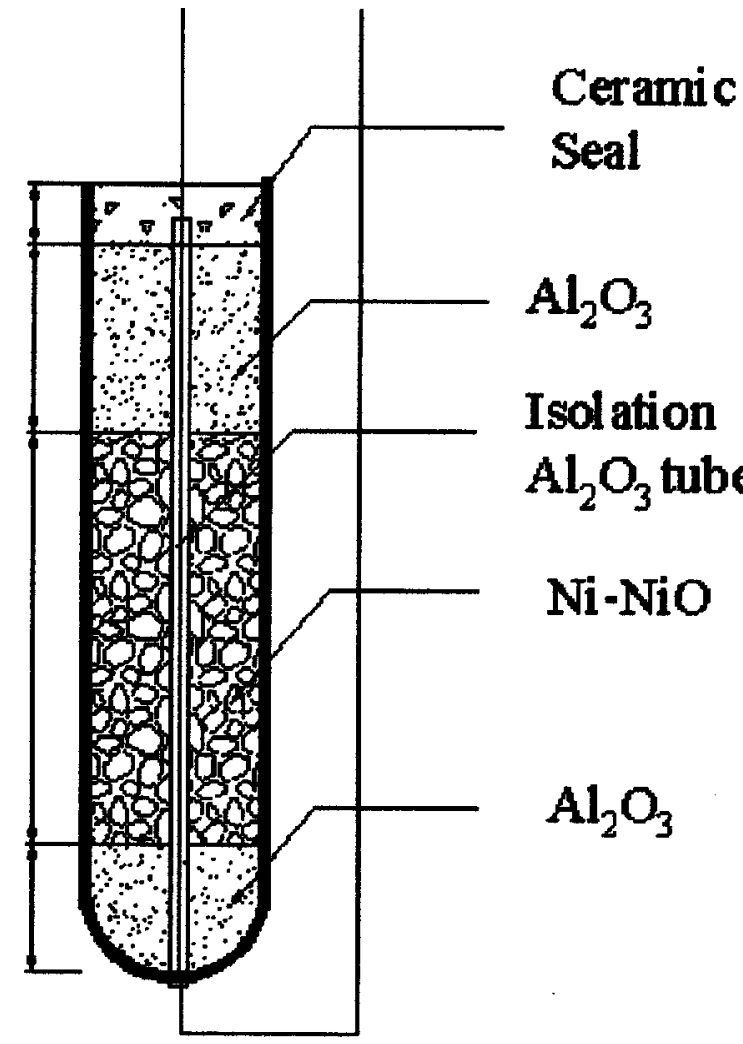

Figure 1. Schematic of the sensor probe showing the isolation using alumina.

rest of the tube was packed with $\mathrm{Al}_{2} \mathrm{O}_{3}$ powder to fill the space. The open end of the tube was sealed with a high temperature sealing material.

Heat-treatment of sealing material.-Two types of sealing materials were used: Resbond 989 and Resbond ceramic binder 794, Cotronics Corp. The first sealing material (989) is an $\mathrm{Al}_{2} \mathrm{O}_{3}$-based porous bonding material. The second sealing material (glass-based, 794) helps seal the pores giving a hermetic seal. After adding the bonding material (989 type) the sample was kept at room temperature for $4 \mathrm{~h}$. After that, the sample was kept at $200^{\circ} \mathrm{C}$ for $4 \mathrm{~h}, 400^{\circ} \mathrm{C}$ for $4 \mathrm{~h}, 800^{\circ} \mathrm{C}$ for $2 \mathrm{~h}$, and $1400^{\circ} \mathrm{C}$ for $1 \mathrm{~h}$. A very slow heating and cooling rate $\left(1^{\circ} \mathrm{C} / \mathrm{min}\right)$ was employed to avoid cracking. After heattreatment of the 989 type was done, 794 type was applied as an overcoat using a fine brush and kept at room temperature for $1 \mathrm{~h}$. The samples were then heated to $79^{\circ} \mathrm{C}$ for $2 \mathrm{~h}, 176^{\circ} \mathrm{C}$ for $2 \mathrm{~h}, 315^{\circ} \mathrm{C}$ for $2 \mathrm{~h}, 600^{\circ} \mathrm{C}$ for $2 \mathrm{~h}$, and $1400^{\circ} \mathrm{C}$ for $1 \mathrm{~h}$. The same heating and cooling rates were employed for the 794 type.

Electrode preparation.-Pt ink (Engelhard Platinum ink) was painted on both sides of the closed-end tip of the YSZ tube. Fine mesh $\mathrm{Al}_{2} \mathrm{O}_{3}$ particles were mixed with the Pt paste in the green state to help form a mechanically stable electrode. For electrical connection, Pt lead wires were attached to the coated portions of the YSZ tube when the paint was in the green state. The assembly was kept in air for $2 \mathrm{~h}$. It was then cured at $1250^{\circ} \mathrm{C}$ for $6 \mathrm{~h}$. A heating and cooling rate of $5^{\circ} \mathrm{C} / \mathrm{min}$ was maintained as recommended by the ink manufacturer. Typical ink contains $80 \%$ metal and 20\% organic binder. These organic substances evaporate during heat-treatment and make the electrode porous; they play the key role as the "gasmetal-oxide three-point contact."'

Sensor test procedure.-The fabricated sensors were tested in a tube furnace $\left(1500^{\circ} \mathrm{C}\right.$ Lindberg). The samples were placed at the center of an open-end quartz tube. This quartz tube was placed in
Table I. Comparison of the experimentally observed $d$ values with those theoretically calculated from diffraction data.

Diffraction planes $(h k l)$ Calculated $d$ value $(\AA)$ Observed $d$ value $(\AA)$

\begin{tabular}{lll}
\hline 100 & 2.140 & 2.09816 \\
200 & 1.860 & 1.81906 \\
220 & 1.316 & 1.28966
\end{tabular}

the furnace. A constant gas flow was maintained with varying oxygen concentrations through the tube. Mass flow controllers calibrated before the experiments maintained gas flow. The electrodes of the sensor were connected to a HP multimeter and the corresponding emf at a certain temperature and oxygen concentration was recorded.

Characterization.-A Scintag PAD-V X-ray diffractometer was used for phase analysis. The instrument is fitted with a $\mathrm{Cu}$ anode, 2 $\mathrm{kW}$ sealed tube X-ray source. A Philips XL-30 FEG scanning electron microscope (SEM) was used to observe the morphology of the inner and outer Pt electrode. Chemical composition of the outer $\mathrm{Pt}$ electrode and the $\mathrm{Ni}-\mathrm{NiO} /$ inner Pt electrode interface were analyzed by using energy dispersive X-ray (EDX) DX-4 with a sapphire detector having a super ultrathin window (SUTW) installed in the XL-30 FEG SEM apparatus. The EDX instrumental error is $<5 \%$.

\section{Results and Discussion}

From the results of the XRD analysis on Ni-Pt powder mixture heat treated at $1200^{\circ} \mathrm{C}$, it is seen that the peaks resulting from the solid solution lie in between the expected peaks for pure $\mathrm{Ni}$ and pure Pt. This is as expected with respect to a solid solution. Both pure Ni and Pt crystallize in the face-centered cubic (fcc) structure, with lattice constants of 3.5238 and $3.9231 \AA$ A, respectively. Vegard's law for a solid solution states that the lattice parameter for a substitutional solid solution depends on the weight fraction of each component, and is a weighted mean of the lattice constants of the two components. Accordingly, the lattice constant for a 50-50 wt \% $\mathrm{Ni}$-Pt solid solution would be the arithmetic mean of the lattice constants of pure $\mathrm{Ni}$ and pure Pt, and is estimated to be $3.72385 \AA$. Using this lattice constant, $d$ values for the corresponding lattice planes in an fcc crystal were calculated. These $d$ values were then compared with the observed $d$ values from the diffraction pattern. As listed in Table I, within experimental uncertainty, the calculated and the observed values match reasonably well. Based on this agreement, along with the fact that the peaks in the diffraction pattern lie

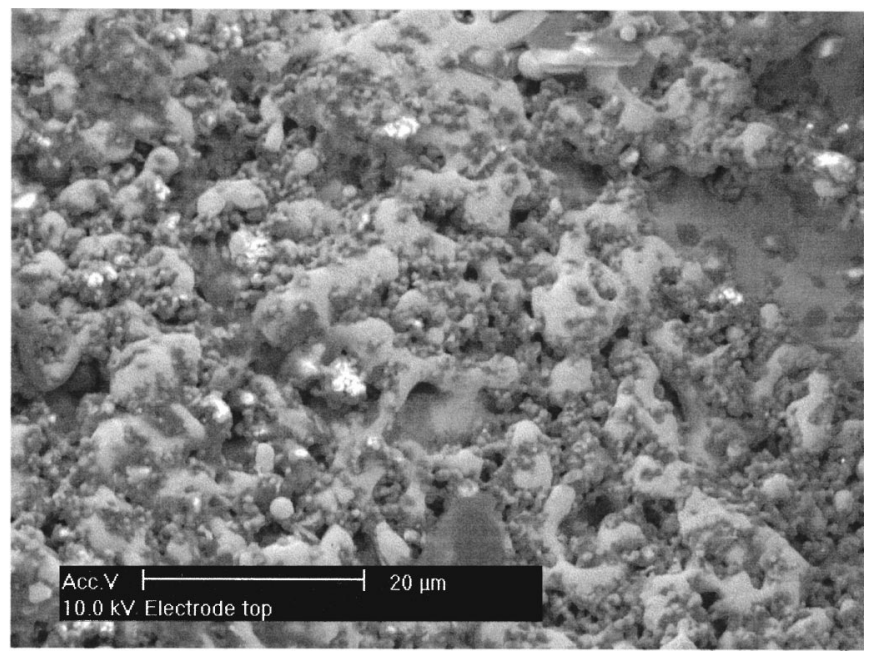

Figure 2. SEM image showing outer Pt electrode. Dispersed $\mathrm{Al}_{2} \mathrm{O}_{3}$ particles are also observed. 


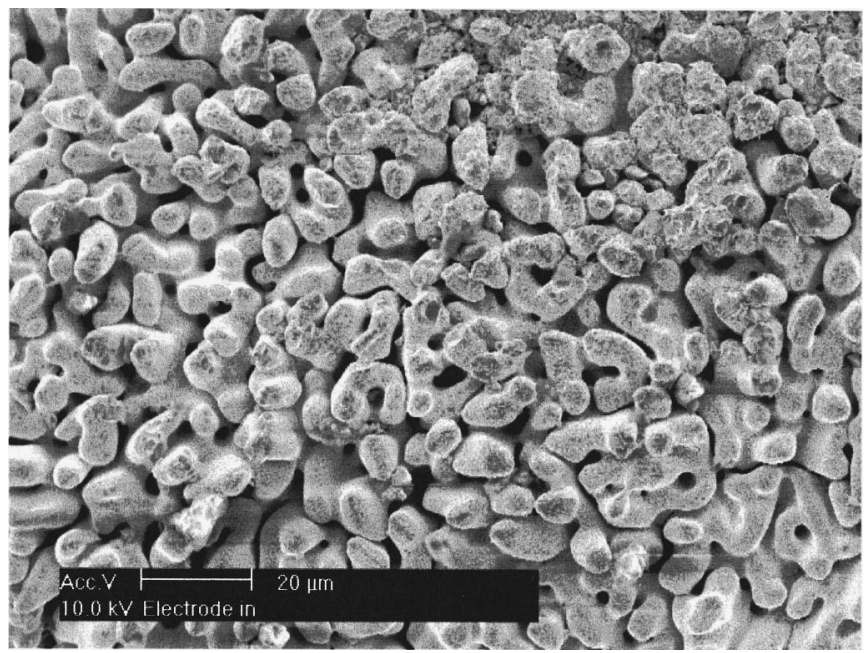

Figure 3. SEM image showing the inner electrode with evidence of grain growth and sintering.

in between the peaks for pure $\mathrm{Pt}$ and pure $\mathrm{Ni}$, we can conclude that a solid solution is formed between $\mathrm{Ni}$ and $\mathrm{Pt}$ at the heat-treatment and working temperatures of the sensor.

Figure 2 shows the SEM image of the outer Pt electrode tip. The outer $\mathrm{Pt}$ electrode is porous and dispersed $\mathrm{Al}_{2} \mathrm{O}_{3}$ particles can be observed. These powders were mixed with the Pt paste in the green state. During curing of the $\mathrm{Pt}$ paste, these powders help formation of mechanically stable electrode. Figure 3 shows the SEM image of the inner Pt electrode. The inner Pt electrode is morphologically different from the outer one, although the same Pt paste was used for electrode preparation. The inner electrode is also porous, but there is evidence of grain growth and sintering. During $\mathrm{Ni}$ and $\mathrm{NiO}$ powder mixing, $\mathrm{NiO}$ was dispersed in such a manner that some of it was agglomerated. This agglomerated $\mathrm{NiO}$ is seen in several locations on the inner Pt electrode as evident in the micrograph (Fig. 4). As Ni forms solid solution with $\mathrm{Pt}$, the $\mathrm{Ni}$ part in the original $\mathrm{Ni}-\mathrm{NiO}$ mixture becomes less at the interface leaving these NiO chunks on $\mathrm{Pt}-\mathrm{Ni}$ alloy surface. The dispersion of $\mathrm{NiO}$ directly on Pt surface along with grain growth at a high temperature of operation would change the inner electrode characteristics from the outer one, making the sensor unstable.

To prevent the interaction of $\mathrm{Ni}$ with $\mathrm{Pt}$, and thus avoid solid solution formation, $\mathrm{Pt}$ wire was isolated from the $\mathrm{Ni}-\mathrm{NiO}$ mixtures

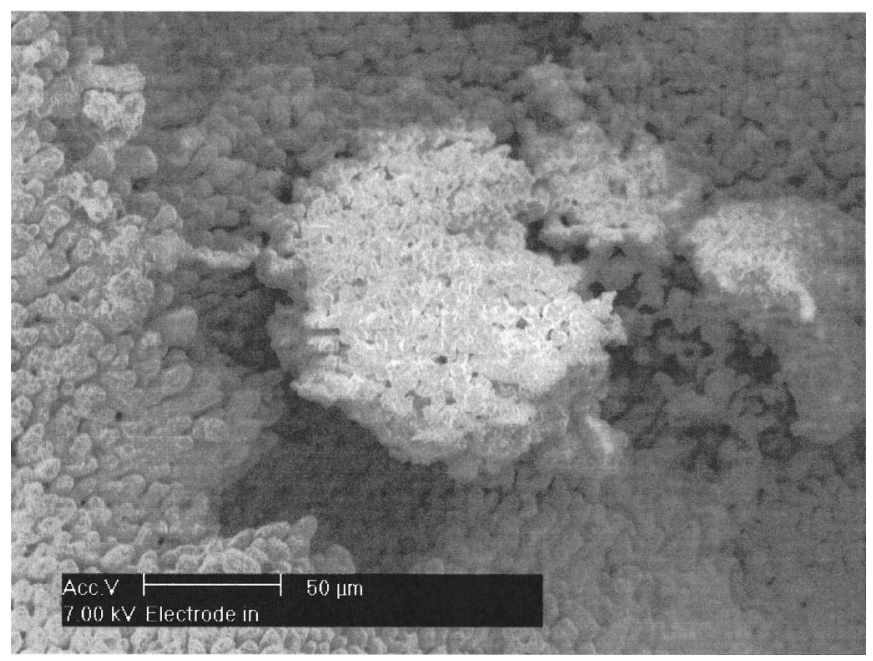

Figure 4. SEM image showing $\mathrm{NiO}$ on top of the inner Pt electrode.

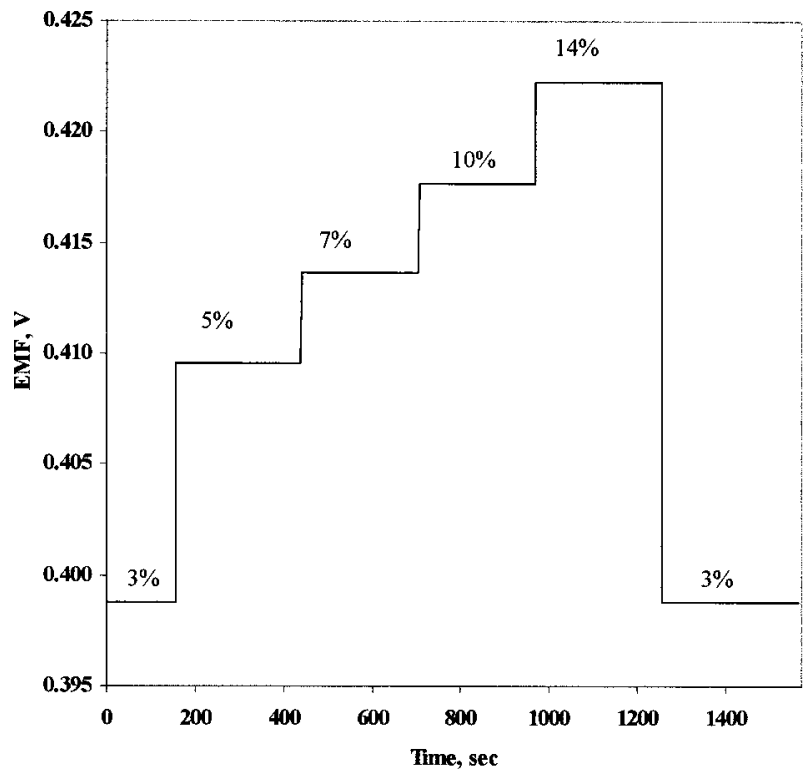

Figure 5. Response characteristics of a stable sensor at $1200^{\circ} \mathrm{C}$ at different oxygen concentrations.

using an $\mathrm{Al}_{2} \mathrm{O}_{3}$ tube. Figure 5 shows the response characteristics of the sensor having isolation between inner Pt electrode and $\mathrm{Ni}-\mathrm{NiO}$ solid reference at $1200^{\circ} \mathrm{C}$. The data show good response and recovery characteristics. The $90 \%$ response time is as short as a few seconds and the recovery time is less than $20 \mathrm{~s}$.

Figure 6 shows the emf signal as a function of oxygen concentration (logarithmic scale) showing the Nernstian behavior of the sensor at $1200^{\circ} \mathrm{C}$. The theoretical values estimated based on the Nernst equation and the experimental data are shown. It can be seen from the figure that whereas the slopes are practically identical, the experimental and theoretical data are offset by a constant amount. This is because practically it is difficult to prepare identical Pt electrodes on the inner and outer surfaces of the YSZ tube. These dissimilar Pt surfaces produce the observed difference in the numerical values.

Figure 7 shows the response of the sensor along with reversibility behavior at $1400^{\circ} \mathrm{C}$. This response along with those observed at $1200^{\circ} \mathrm{C}$ indicates that the sensor is leak free and shows good response characteristics up to $1400^{\circ} \mathrm{C}$ in the short term. However, after repeated tests over a longer period, the sensor performance degraded. A noticeable amount of drift was observed in the sensor signal, when the sensor was continuously tested at $1250^{\circ} \mathrm{C}$ in air over 3.5 days. The output voltage drifted at the rate of about 5 $\mu \mathrm{V} / \mathrm{min}$. This drift possibly arises due to grain growth and sintering of the inner electrode. So, in addition to isolating the metal/metal oxide mixture from $\mathrm{Pt}$, one must find a system that does not sinter at the operation temperature.

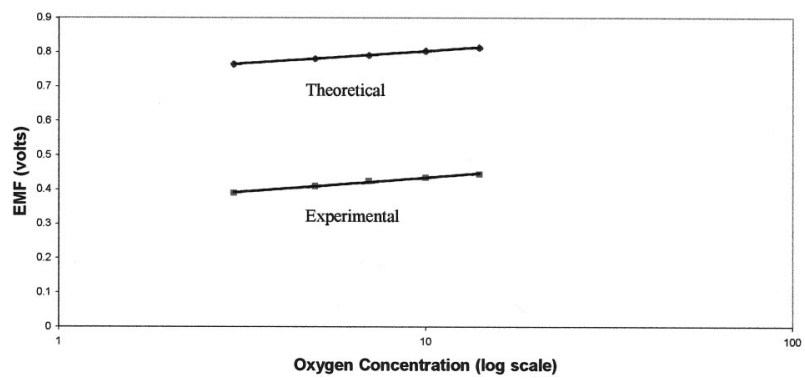

Figure 6. Comparison of the theoretical and experimental data at $1200^{\circ} \mathrm{C}$ showing the Nernstian slope. 


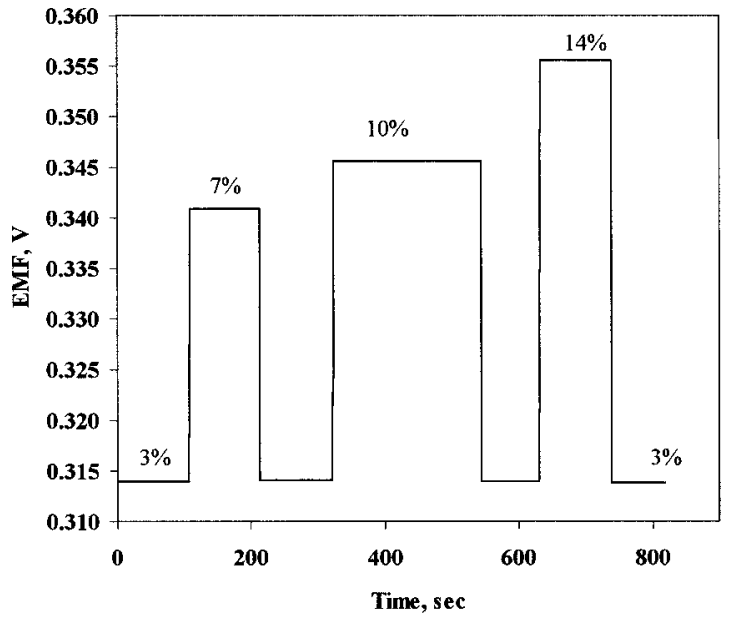

Figure 7. Response and reversibility test of an oxygen sensor at $1400^{\circ} \mathrm{C}$.

\section{Conclusions}

For high temperature (in the range of $600-1400^{\circ} \mathrm{C}$ ) use, an oxygen sensor based on a solid reference electrode using $\mathrm{Ni}-\mathrm{NiO}$ has been designed and tested. An optimized heat-treatment procedure has been developed for curing of electrode and sealing materials. The response and recovery are fast with $90 \%$ response time as short as a few seconds and recovery time $<20 \mathrm{~s}$. The sensor shows a Nernstian response with a constant offset in signal magnitude due to dissimilar electrodes formed during Pt paint curing on the two sides of the closed-end YSZ tube. Metal-metal oxide (Ni-NiO) solid reference oxygen sensors become unstable and cannot be considered for long-term use due to formation of Pt-Ni alloy. To avoid this alloy formation $\mathrm{Pt}$ lead wire and electrode were isolated from the $\mathrm{Ni}-\mathrm{NiO}$ mixture by using ceramic isolation $\left(\mathrm{Al}_{2} \mathrm{O}_{3}\right)$. The sensor with the isolation gives stable performance in the temperature range of $600-1400^{\circ} \mathrm{C}$ in the short term. It also gives considerably stable results in the long term up to about $1000^{\circ} \mathrm{C}$. However, the sensor suffers from long-term stability at temperatures in the range of $1200-1400^{\circ} \mathrm{C}$, possibly due to grain growth and sintering of the inner electrode. So, in addition to isolating the metal/metal oxide mixture from $\mathrm{Pt}$, it is necessary to find a system that does not sinter at the operation temperature.

\section{Acknowledgments}

This work was supported by a grant from the National Science Foundation (EEC-9523358) with matching support from Orton Ceramic Foundation. Technical discussion with Professor Sandhage is acknowledged.

The Ohio State University assisted in meeting the publication costs of this article.

\section{References}

1. A. Kohli, C. C. Wang, and S. A. Akbar, Sens. Actuators B, 56, 121 (1999).

2. C. B. Alcock, Rev. Int. Hautes Temp. Refract., 28, 1 (1992-93).

3. J. Baglin, F. D'Heurle, and S. Zirinsky, J. Electrochem. Soc., 125, 1854 (1978)

4. L. Brewer and R. H. Lamoreaux, II. Phase Diagrams, Volume Atomic Energy Rev., Spec. Issue no. 7, p. 344, International Atomic Energy Agency, Vienna (1980).

5. D. V. Ragone, Thermodynamics of Materials, Vol. 1, p. 156, John Wiley \& Sons, Inc., New York (1995)

6. C. P. H. Lupis, Chemical Thermodynamics of Materials, p. 134, Elsevier Science Publishing Co., Inc., New York (1983).

7. A. K. M. S. Chowdhury, S. A. Akbar, and J. R. Schorr, in Chemical Sensors IV, M. A. Butler, N. Yamazoe, P. Vanysek, and M. Aizawa, Editors, PV 99-23, p. 1, The Electrochemical Society Proceedings Series, Pennington, NJ (1999).

8. C. E. Dahmani, M. C. Cadeville, J. M. Sanchez, and J. L. Moran-Lopez, Phys. Rev. Lett., 55, 1208 (1985). 